\title{
IMPACTS OF BLENDED LEARNING SYSTEMS ON AOU STUDENTS' SATISFACTION: AN INVESTIGATIONAL ANALYSIS OF KSA'S BRANCH
}

\author{
Dr. Hussein AL-BAZAR \\ ORCID: 0000-0002-2173-1588 \\ Faculty of Computer Studies \\ Arab Open University \\ Dammam, SAUDI ARABIA \\ Dr. Hussein ABDEL-JABER \\ ORCID: 0000-0001-9372-4558 \\ Faculty of Computer Studies \\ Arab Open University \\ Dammam, SAUDI ARABIA \\ Dr. Ebtisam LABIB \\ ORCID: 0000-0001-6185-6046 \\ Faculty of Business Studies \\ Arab Open University \\ Dammam, SAUDI ARABIA \\ Dr. Mohammad AL-MADI \\ ORCID: 0000-0001-9941-039X \\ Faculty of Computer Studies \\ Arab Open University \\ Dammam, SAUDI ARABIA
}

Received: 23/08/2020 Accepted: 23/12/2020

\begin{abstract}
Nowadays, blended learning represents a combination of both e-learning and Face-to-Face learning approaches, which has been considered as an emerging concept of modern education. It has been regarded as a prominent alternative learning approach compared to the conventional e-learning approach. The degree of satisfaction of students with blended learning played a crucial role in evaluating the effectiveness of adopted techniques for blended learning. Therefore, this study examines a number of key factors that affect students' satisfaction within a blended learning environment among undergraduate students involved in a private university in Saudi Arabia. In this paper, a comprehensive online questionnaire is used to assess the impact of blended learning based on seven factors of the blended learning environment. The respondents for this study are generally 221 young undergraduate students with an average age of 20-30 years old. The collected data is analysed by using SmartPLS 3. The results reveal that students are mostly satisfied with the blended learning factors, particularly, with the convergence of the Face-to-Face and Videoconferencing classes and the role of their instructors. Those students are moderately satisfied with the SIS, the online forums, and their course materials and modules, and least satisfied with the LMS and the E-library factors. Accordingly, the suggested recommendations pertaining to the future research are highlighted where this paper offers useful insights for future researchers based on different empirical evidences.
\end{abstract}

Keywords: Blended learning, online learning, students' satisfaction, learning environment. 


\section{INTRODUCTION}

With the enormous improvements on specifications and technologies of computer systems, learning methods have changed in order to exploit the benefits pertaining to these developments. In earlier stages, the conventional face-to-face educational method is used to deliver the classes as a single approach that is available for supporting the educational process between face-to-face students and instructors so that this process could be available within the same location and time. Due to the current increase in the use of the Internet, modern computer systems, multimedia technologies, smart computer applications and learning methods take an advantage of these technologies by combining the face-to-face method and online learning together into a single and effective approach, known as the 'blended learning' approach. Such an approach is currently considered as a new educational paradigm that integrates online learning and conventional learning. In fact, the approach gained huge popularity by many universities, educators and academic institutes in order to support the learning process (Friesen, 2012; Ismail, 2018; Lalima \& Dangwal., 2017), particularly, with the current situation due to the Coronavirus (COVID-19) pandemic.

The blended learning approach is devoted to improving the delivery of its methods by providing further effective learning environments (Giannousi et al., 2009; Kavitha \& Jaisingh, 2019). Many advantages are delivered by this approach for all types of users (students, tutors and academic members). Such advantages include the location's flexibility for students to attend online classes, the cost reduction for educational institutes, online discussion groups between students and tutors, online updated materials that are available and accessible anytime and anywhere, e-library, online announcements for all students through different learning modules such as the Learning Management System (LMS), and online assessments (Eryilmaz, 2015; Khan et al., 2012; Shivam \& Singh, 2015). Additionally, this approach provides multiple characteristics for all users where students and tutors have the opportunity to conduct several communications and interactive activities. These communications involve face-to-face and online tutorials, improving students' skills, experiencing through exploring and using up-to-date technologies within the academic domain, multicultural and multi-measurement methods when dealing with the learning process, and self-motivation and knowledgeable information for as many students as possible (Lalima \& Dangwal, 2017).

Many researches focus on evaluating the effectiveness of blended learning by analysing a set of important factors in order to investigate the satisfaction level. In Ismail (2018) research, the main factors that affect learners' satisfaction are examined. Other studies investigate the effects of the blended learning instructions on the context of students' satisfaction (Ghaderizefreh \& Hoover, 2018; Giannousi et al., 2009; Wu, Tennyson, \& Hsia, 2010), including the effects on students' performance in the context of educational environments (Afacan, 2018), or the effects on providing a comparative analysis for understanding the level of students' satisfaction (Almarashdeh et al., 2018). Further, all related studies agree on the fact that students' satisfaction is the most crucial factor that directly affects the effectiveness and measures of several blended learning systems. Students' satisfaction is considered as an evaluation of several outcomes and practices in the context of students' participation (Roslina, Nur Shaminah, \& Sian-Hoon, 2013). The contribution of this study examines the impact of blended learning systems on students' satisfaction (SS). A comprehensive questionnaire includes seven main factors, which comprise Instructors (INST), Modules (MOD), e-library (ELIB), Learning Management System (LMS), Student Information System (SIS), Online Discussion Forums (FORM), and Face-to-Face and Videoconferencing Classes (F2F). These factors are used to assess students' levels and the impact of blended learning systems on them. Moreover, the study is conducted at the Arab Open University (AOU), which contains six different branches among the Kingdom of Saudi Arabia. In fact, this university is represented as a leading university that adopts the bended learning system through its educational processes.

\section{LITERATURE REVIEW}

Several researchers have introduced extensive studies regarding the satisfaction of students in the blended learning approach. In fact, this approach is considered as a current and valuable educational approach that is based on merging between online learning and face-to-face conventional learning (Bahati et al., 2019; Kang \& Seomun, 2018; Li et al., 2019). A number of experiments has currently been performed through several educational institutions for the aim of investigating and analysing the efficiency pertaining to many different 
blended learning environments (Kavitha \& Jaisingh, 2019). It is found to be proven from some studies that students gain valuable experiences and skills in dealing with various communicational technologies and information when adopting this approach into their studies (Kavitha \& Jaisingh, 2019; Kavitha, Jayalakshmi, $\&$ Rassika, 2018). Furthermore, many factors have been currently affecting the satisfaction of students in a number of educational institutions in order to assist educational leaders in providing their decision makings for building an efficient strategy that can determine possible factors of students' satisfaction (Hutabarat, Hutabarat, \& Hutabarat, 2020).

Due to the importance of the blended learning approach, many researchers have far been contributing to investigate the influences of such an approach through many different educational environments. For instance, the researcher by Eryilmaz (2015) measures the impact of blended learning on online learning and face-to-face learning domains. Eryilmaz (2015)'s study is applied on 110 students at the Atilim University in Istanbul, Turkey. The analytical results demonstrate that there is a significant difference based on a convergence between students' perspectives to blended learning and face-to-face online learning domains. Students' responses show that blended learning has been effectively adhered to their learning and experiences. Based on their answers, students expressed that they are able to learn more effectively within a blended learning environment. Additionally, the researchers Keskin \& Yurdugul (2019) provide an analysis for different factors, which are individually taking place by influencing the mode of learners in achieving effective learning and teaching outcomes. In their research, optimal scaling analysis is used for data analysis purposes where two-dimensional centroid graphs are applied among various variable categories by demonstrating the correlations within them. As a result, it has been found that the preferences pertaining to their learning environment have proven to demonstrate correlation among them including the task value, e-learning motivation and creating self-efficacy. Similarly, Stefanic et al. (2020) conducted a study to provide investigational perceptions of students based on a cross-cultural entrepreneurial blended learning module. An investigation is also conducted for the situation of socioeconomic perception on the satisfaction of a number of participants for a particular module. Further, their research elaborates how learning is active and how current responsibilities are incurred in students and teachers through the perspective of cross-cultural setting within the eastern and western European countries'settings. At the end, it is found to be revealed from the findings that the technical side itself of a course delivery is insufficient without the observations, supports and expectations of students in the course-learning domain.

In Bouilheres et al. (2020)'s research, the valuable gains of the blended learning approach are investigated for assessing the experiences of how students are able to learn at a particular offshore campus related to an Australian university in the city of Ho Chi Minh, Vietnam. In fact, the main idea behind their research is based on its efficiency and practicality in developing collaboration and learning environments among students themselves, and between their course materials and teachers. The results indicate that these students provide different responses when achieving their learning skills through this approach and through acquiring its usefulness. In the same context, an effective involvement of students with their teachers and peers based on their high motivation in different learning methods is introduced by Collaco (2017). The findings show that this involvement comprises affective, interpersonal and behavioural elements, which should be taken into account when there is a demand for an authentic involvement within a learning environment. Moreover, the effectiveness of the blended learning approach is investigated by Kintu, Zhu, \& Kagambe (2017), in order to analyse different features related to students toward this approach. In particular, these features comprise their original backgrounds, learning designs and learning outcomes. The research findings in Kintu et al. (2017) indicate that few backgrounds and learning designs of some students represent valuable predictors for their learning outcomes in the blended learning approach. Another similar study is conducted by Li et al. (2019) where they provide a meta-analysis research on the influences of the blended learning approach on the satisfaction, skills and knowledge of particular nursing students. The findings of Kintu et al. (2017) study demonstrate that an overall of eight studies achieve the meta-analysis's inclusion criteria, involving a number of 574 nursing students in comparison with the conventional teaching approach. Accordingly, they prove that this approach can positively enhance the knowledge, skills and satisfaction of these students. In fact, Sherman et al. (2012) argue that a few studies demonstrate that the blended learning approach develops the professional knowledge in nursing students. On the other hand, it is stated by Kaveevivitchai et al. (2009) that this approach can also develop the performance skills of nursing students rather than only developing their acquired knowledge. 
To the best knowledge of the researchers Li et al. (2019), there are no existing methodical studies of the blended learning approach that have far been conducted for nursing students. Hence, the current paper investigates the impacts of different blended learning systems on the educational domain, particularly, on the students' satisfactions who are currently studying at the Arab Open University in Saudi Arabia. In the blended learning approach, further researches in the satisfaction of students is also introduced by Masrom, Alwi, \& Asshidin (2019) where an investigational study on how learners are satisfied with the involvement of such an approach is provided. In their research, descriptive statistics are applied to analyse the satisfaction of learners along with their demographical information when proceeding towards the blended learning approach. It is found to be proven from their research that the satisfaction of a number of learners in this approach achieves effective benefits to them through their institutions. Nonetheless, few researchers like Zhai et al. (2017) and Masrom et al. (2019) mention the necessity of depending on the satisfaction of learners in this approach according to their acquired learning experiences. The importance behind this necessity refers to the fact that comprehending the 'grasp' of the satisfaction of learners in the blended learning approach plays a significant role in integrating the components of any given course. Consequently, creating a convenient and an appropriate environment for learners towards blended learning is possible and manageable (Masrom et al., 2019).

Previous researches that are devoted to enhancing learners' satisfaction mention that the blended learning approach can also increase the effectiveness of students' influences on their academic performances and on their ability to understand and learn (Anaraki, 2018). Additionally, it is assured by Botha (2018) that further assistance can be possibly provided to learners by their trainers for the aim of sustaining an efficient online platform based on the blended learning approach. An examinational study of the influence of the blended learning approach on the Community of Inquiry (CoI) pertaining to high school learners is introduced by Harrell \& Wendt, (2019). A similar study is carried out by Roslina et al. (2013) where it is revealed that the satisfaction of students in the blended learning approach is based on a tertiary course held in a Malaysian university. In particular, their research aims at testing students' views in this approach based on proceeding further with this course in order to test the future paths related to the domain of this approach. Despite the fact that their findings achieve more negative responses than positive responses, Roslina et al. (2013) believe that the approach should be put for further effective implementation, which can bring many benefits to its learners. Based on the measurement of responses, a developed method, namely, the 'Moore Interaction' method is applied by Commissiong (2020) for creating a new tool that can measure learners' and faculty's self-reported responses. In fact, this method is selected and validated based on experts in the field when using different statistical approaches. It is found to be proven from the results of Commissiong (2020) 's study that the views of students' success are predicted in relation to students' satisfaction, self-regulation and engagement. Subsequently, these results cause an effective change on the social domain based on the way universities attempt to apply instructional and learning processes in many environments related to the online learning approach.

On the other hand, many other researchers focus on investigating different studies that are based on understanding the perceived learning approach along with the blended learning approach (Akyol \& Garrison, 2011; Keramidas, 2012; Larson \& Sung, 2009; Lim, Morris, \& Kupritz, 2007). As indicated by Rovai \& Baker (2005), it is supposed that the self-reported perceived learning of students can reveal their views according to the effectiveness of various educational modules. At later stages, the Cognitive, Affective, and Psychomotor (CAP) perceived learning scale is improved in Rovai \& Baker (2005) research in order to provide effective measures, which are related to the perceived learning approach. According to Rovai et al., (2009), this scale provides the ability to investigate different aspects related to the educational effectiveness based on a variety of layouts, modules and teachers for comprehending the Community of Inquiry (CoI)'s effectiveness including blended and online learning domains. Additionally, it is pointed out by Askar, Altun, \& Ilgaz (2008) that it is significant to test how perceived learning on students' ability to learn modules is achieved through many blended learning environments.

It is important in this paper to point out that the selected factors in the theoretical framework are derived from different studies in the literature (Almarashdeh et al., 2018; Keskin \& Yurdugul, 2019; Roff, 2018; Stefanic et al., 2020). Additionally, these factors are derived from the current blended learning environment and systems conducted by the AOU in the KSA. In other words, these factors underpin the research of this paper in order to conduct the questionnaires and effectively deliver the investigational analysis and results. For example, it is indicated by Hutabarat et al. (2020) that the obtained results show that the 
'academic courses' factor has positively achieved many respondents' satisfactions based on their undertaken courses. In the context of the research paper, this underpins the use of the 'module' factor for achieving students' satisfaction in the blended learning approach. Furthermore, it is contended by Askar et al. (2008) that the 'face-to-face environment' factor contributes to achieve learners' satisfaction. Similarly, the paper also underpins this factor by using the 'face-to-face videoconferencing' factor for investigating students' satisfaction in this approach. Therefore, the following hypothesis is proposed:

H1: There is a positive relationship between blended learning and students' satisfaction.

To provide a critical analysis of the literature, it is worth highlighting and summarising what the state-ofthe-art research has investigated in the blended learning approach. In view of the foregoing researches, the approach is stimulating for many arising factors, which may put an impact on its effectiveness. In fact, it can be inferred from the aforementioned studies that most researchers aim to study the influence of blended learning on students' satisfaction and performances. However, many other researchers have conducted an extensive study on how perceived learning affect the level of students' understanding by either acquiring knowledge from an instructor-to-student interaction or course-to-student interaction. In conclusion, it can also be observed from the literature that further extensive investigations should be studied based on more factors other than just limited factors as students' satisfactions, effectiveness, experience, performances and some other few factors when acquiring learning from teaching within a blended learning environment.

\section{THEORETICAL FRAMEWORK}

The theoretical framework pertaining to this paper comprises three stages, which include the theoretical factors that are adopted from the Arab Open University (AOU) in the KSA, the primary research and the contribution to the body of knowledge. A number of factors are also derived from the literature (see Figure 1). Seven adopted factors create the initial stage related to this framework, which depend on the Arab Open University (AOU) of the KSA's branch. These factors comprise the Instructors, Modules, E-library, Learning Management System (LMS), Student Information System (SIS), Online Discussion Forum (on SIS), Face-toFace and Videoconferencing Classes. In fact, they are assessed and analysed according to the primary research stage, which represents the second stage of the theoretical framework. In this stage, a comprehensive data analysis is explained in detail leading to obtaining the results of the derived analysis. The final stage introduces the contribution stage as can be seen from Figure 1 where it relates to the literature and obtained findings from the primary research stage. The contribution of this paper aims at testing the influence of the blended learning approach based on different systems on the satisfaction of students who are studying at this university.

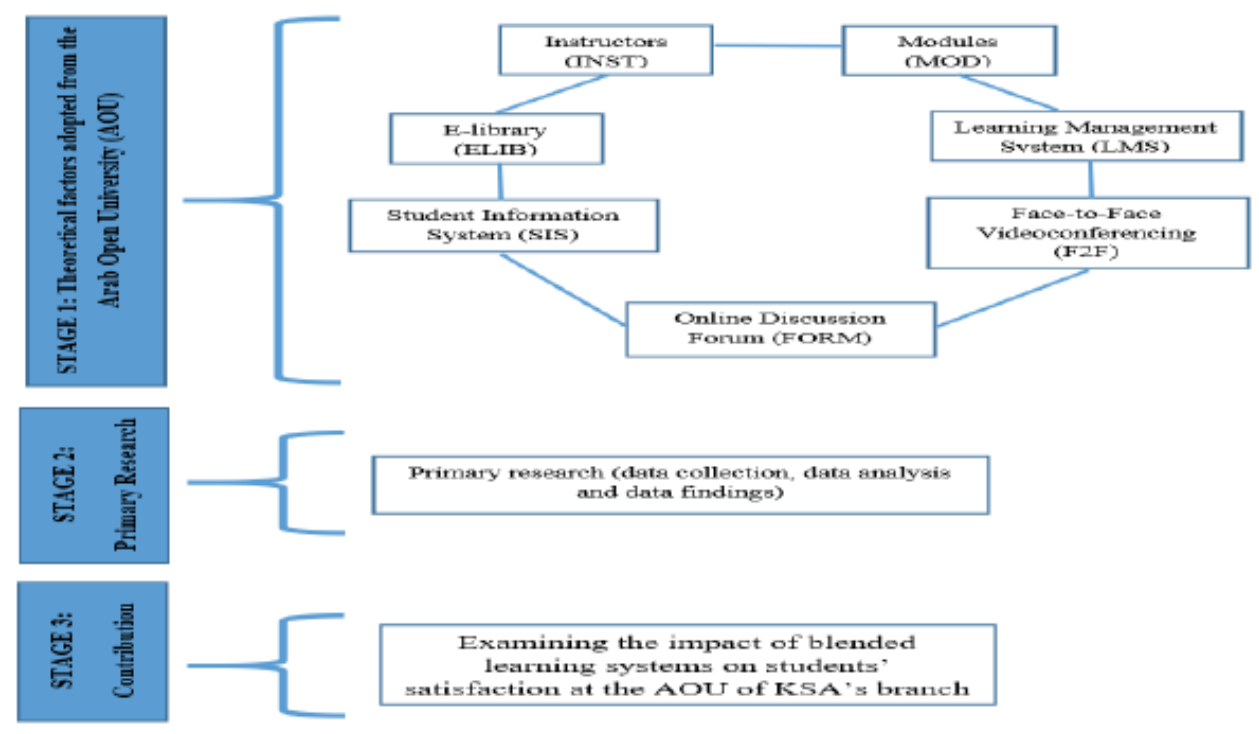

Figure 1. The produced theoretical framework. 


\section{THE FACTORS OF THE BENDED LEARNING APPROACH}

In this section, seven factors of the blended learning approach are presented. The following subsections address and discuss the previously mentioned factors pertaining to the blended learning approach, and the overall students' satisfaction.

\section{Instructors (INST)}

Instructors are one of the factors that can be involved in achieving students' satisfaction. In particular, they are required to be available in order to reply to students' inquiries in an effective manner. Moreover, responses to students should not take longer periods than normally should be (Bi \& Shi, 2019; Joel \& Christina, 2018). Students can receive clear and adequate feedback on their works from their instructors. The interaction between instructors and students is carried out conveniently. Students have effectively learned the modules' contents from their efficient instructors. Emperically, it is found to be proven that the blended learning strategy can enhance and improve students' achievements and satisfactions with their learning (Ismail, 2018). Further, it is demonstrated by Eastman, Aviles, \& Hanna (2017) that the perceived learning approach is positively related to the instructor-to-student interaction. These instructors have to understand how to use the environment, systems and tools of the blended learning approach. Thus, the following hypothesis is proposed:

H1a: There is a positive relationship between instructors' role and students' satisfaction.

\section{Modules (MOD)}

The modules in blended learning are required to be made available and accessible anytime and anywhere. This process can enable students to reach these modules anytime and anywhere without any difficulties. The materials and resources related to the modules should be sufficient and of quality (Hadullo, Omwenga, \& Oboko, 2017). Moreover, Rockinson-Szapkiw et al. (2016) concluded that the perceived learning approach achieves a positive link on the course elements of students, leading to a positive link to the produced outcomes of their acquired learning. Rovai \& Baker (2005) supposed that the self-reported perceived learning of students can reveal their views according to the effectiveness of various educational modules. Additionally, the assessments of the modules should cover all the learning outcomes related to these modules. Instructors should be available in modules' office and E-office hours in order to be able to reply to students' inquiries, and these modules' office and E-office hours should be sufficient and helpful. E-office hours are provided through the videoconference classes. The announcements and news of the modules should be effective, helpful and displayable to students in appropriate times. Grades are announced to students according to a scheduled timetabling, and hence, the following hypothesis is proposed:

H1b: There is a positive relationship between the courses materials, modules and students' Satisfaction.

\section{E-Library (ELIB)}

Students demand the access through to the E-library anytime and anywhere in order to obtain the benefits from it (Holley \& Powell, 2004; Sherifi, 2015). This, in fact, leads to the necessity of an available E-library for students anytime and anywhere. The E-library should contain many resources in different areas that can assist students to gain the knowledge and information they need to accomplish their learning, assignments and improve their education. The resources of the E-library should be adequate, of quality and helpful to students. Furthermore, it should be effective and easily used. This enables students to utilise it in an effective manner. Technical staff members can assist in providing adequate and efficient supporting services of the E-library. To investigatestudents' satisfaction with e-services at Jerash University, Aljaraideh and Rabee (2018) conclud that students' satisfaction toward the university e-services, including E-library resources are found to be moderate. On the other hand, Kara, Tanui and Kalai (2016) conduct a study for assessing how Kenyan students are satisfied with public universities based on the quality of academic resources, which are offered to them. The results of their research demonstrate a positive relationship between students' satisfactions and teaching facilities, including e-library services. Consequently, the following hypothesis is proposed:

H1c: There is a positive relationship between the university's E-library and students' satisfaction. 


\section{Learning Management System (LMS)}

The LMS is available to students at all times and it can be frequently accessed and used from any types of devices (Najmi, Jaafar, \& Paiz, 2016; Umek et al., 2015). Instructors should upload all required materials, resources, announcements, and news pertaining to the modules that are made available through the LMS. This can assist students to obtain everything they need from the modules they are already registered in, and hence, the LMS should be effective and easily used by them. The supporting services of the LMS that are executed by the technical support members should be sufficiently and efficiently conducted (Islam, 2014). Moreover, information quality, service quality and the perceived ease of use acquire a significant effect on students's satisfactions (Ohliati \& Abbas, 2019). In 2016, Kasim \& Khalid concluded that students are satisfied with the available features on LMS if such features meet their needs and facilitate their usage by the students. Consequently, the following hypothesis is proposed:

H1d:There is a positive relationship between the university's Learning Management System (LMS) and students' satisfaction.

\section{Student Information System (SIS)}

The SIS is available to students anytime and anywhere where they can frequently access it to register for their modules, obtain their grades, prepare for their appealing applications, and raise complaints, etc. The SIS should be accessible regardless of time and place. The services that are included in the SIS should be adequate and useful for students (Gurkut \& Nat, 2017). This usefulness can enable them to use SIS smoothly and effectively. Technical support members should present adequate and efficient supporting services in the SIS. Accordingly, the following hypothesis is proposed:

H1e: There is a positive relationship between the university's Student Information System (SIS) and students' satisfaction

\section{Online Discussion Forums (FORM)}

Students may frequently use online discussion forums that are made available through the LMS as this system is available and accessible by students at all times. Online discussion forums are efficient and can be smoothly used. Instructors and students can interact with each other by using online discussion forums for discussing the subjects of the prospective modules where all the discussed topics of the modules should be helpful for students (Alzahrani, 2017). Additionally, online discussion fourms can be considered as an open platform, which allows students to share their knowledge, experience, highlighted questions and shared problem-solving cases based on an open discussion between students and their instructors. Hence, this yields the students to enhance their critical thinking skills (Fu et al., 2017). From this point, the following hypothesis is proposed:

H1f: There is a positive relationship between the university's online discussion forums and students' satisfaction.

\section{Face-to-Face and Videoconferencing Classes (F2F)}

Instructors can deliver the tutorials into face-to-face meetings and through different videoconference classes. A videoconferencing system is available and accessible anytime and anywhere where using such a system should be effectively and easily used. The tutorials of face- to-face meetings and videoconference classes should be adequate and motivating to students in order to develop their learning skills in an efficient manner. The resources, software and equipment that are used by face-to-face meetings and videoconference classes should be adequate, effective and of quality. Technical support members should offer sufficient and efficient services for face-to-face meetings and videoconference classes at all times. In fact, robust and positive associations for achieving students' satisfaction of the F2F classes refer back to a research that is carried out by Tratnik, Urh, \& Jereb (2019). Consequently, the results prove that the F2F classes' blended learning 
approach leads to acquire further effective outcomes when students' information is communicated through various pedagogies, which allow them to proceed further along with their studies in an efficient manner (Roach \& Lemasters, 2006). Similarly, Kintu et al. (2017) declared that an efficient relationship exists between students' satisfaction and F2F classes. This is based on recording the F2F classes' score of the average mean that manages students' satisfaction. Consequently, it is found to be proven that the respondents are satisfied with the variable, namely, 'F2F classes', and hence, the following hypothesis is proposed:

H1g: There is a positive relationship between the Face-to-Face and Videoconferencing Classes and students' satisfaction.

\section{Students' Satisfaction}

The overall students' satisfaction is achieved into different blended learning systems by obtaining the following requirements:

- The performance of instructors should be efficient and satisfying.

- The modules should be sufficient and of quality.

- The systems that are used in blended learning systems such as the LMS, E-Library, online discussion forums, SIS, and videoconferencing classes should have a satisfactory performance.

- Instructors need to deliver the followings in an efficient manner. These include face-to-face meetings, videoconference classes, and office and E-office hours.

- Adequate and quality blended learning environment should contribute in achieving students' satisfaction.

\section{THE PROPOSED RESEARCH FREAMWORK}

This research attempts to assess the impact of the seven blended learning factors that are explained previously in order to achieve undergraduates' satisfaction. Moreover, the research differentiates between each effect of a factor on students' satisfaction in order to shed the light on the ones that require an evaluation for attaining higher students' satisfaction. This satisfaction is based on the blended learning environment that is offered by the university. The suggested research framework is outlined in Figure 2.

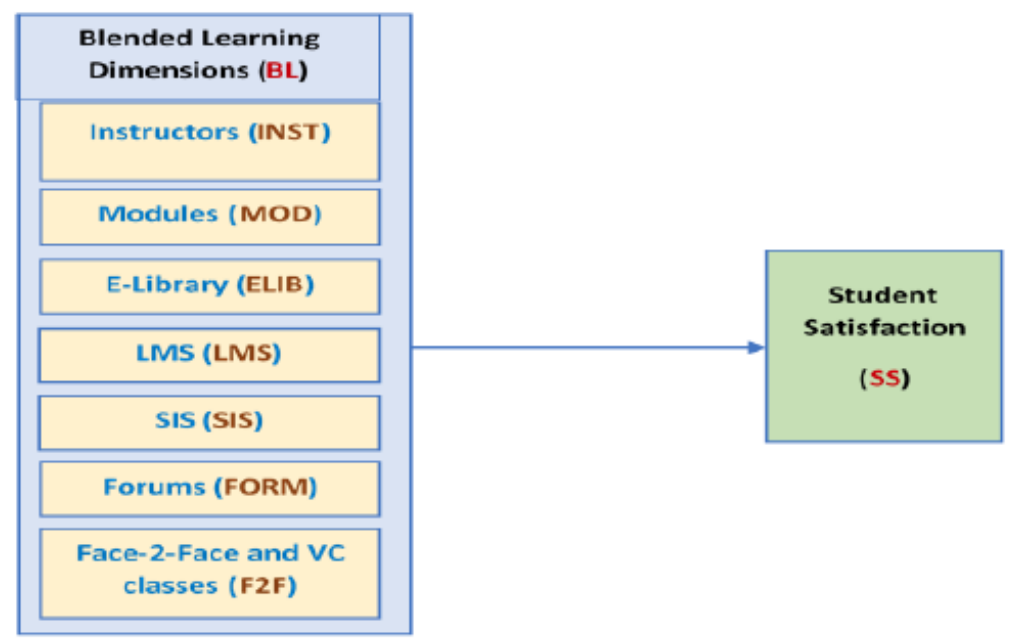

Figure 2. The research framework.

\section{RESEARCH METHODOLOGY}

In this section, the results of the data analysis are elaborated. First, the demographic factors of the respondents to the survey are given. After that, the methods and technologies that are used by the respondents are 
presented. Third, appropriate data analytical techniques are described. Fourth, the obtained findings from the measurement model analysis are highlighted in detail. Finally, the findings from the structural model analysis are given, including the analysis of the hypothesis tests.

\section{Research Design and Sample Template}

This study is based on a cross-sectional survey of full-time undergraduate students that aims at examining the relationships between the use of the blended learning approach and students' satisfaction. To incorporate this approach, a mix of face-to-face teaching accompanied by technology into the classroom is used in the AOU of KSA's branch that applies such an approach that was opened back in 2003. The cross-sectional study design is adopted by conducting data collection at a single point of time (Sekaran \& Bougie, 2016) that is suitable for testing the required hypotheses. The sample of 221 students that are used in the study are randomly drawn from the pool of undergraduate students who are registered at the $\mathrm{AOU}$ in spring semester $2019 / 2020$.

\section{Research Instrument}

Selected respondents voluntarily complete two parts of a given online survey. The first section gathers the demographic and personal data, while the second consists of 45 items based on a 5-point Likert scale that are ranged from ' 1 -Strongly disagree' to ' 5 -Strongly agree' according to positive items, and from '1-Strongly agree' to '5-Strongly disagree' according to negative items. To ensure the inclusion of a comprehensive list of measures, several past relevant studies are reviewed to develop a self-report instrument. These measured items are adopted from various scholars that present different factors, which are central to students' satisfaction in the blended learning environments. After that, these items are adopted based on the AOU's blended learning applied strategies. To enhance the content's validity, expert members in the field who are comprised of four professors, one lecturer and five students are asked to review the involved questionnaires.

\section{DATA ANALYSIS AND RESULTS}

The SPSS (Statistical Package for the Social Sciences) (v.25) tool is used to insert students' responses and to test the normality and Common Method Variance (CMV) where biasness can be induced by the instrument rather than the respondents. Once there is no evidence of a common method variance, the Structured Equation Modelling using Partial Least Squares (PLS-SEM) through the Smart PLS tool is applied in this study in order to examine the relationship between the blended learning dimensions and UG students' satisfaction at the AOU. As suggested by Hair, Ringle, \& Sarstedt (2012) and Hair, et al. (2016)Joseph $\mathrm{F}<$ /author $><$ author $>$ Hult, G Tomas $\mathrm{M}<$ /author $><$ author $>$ Ringle, Christian</author $><$ author $>$ Sarstedt, Marko $<$ /author $><$ /authors $><$ /contributors $><$ titles $><$ title $>\mathrm{A}$ primer on partial least squares structural equation modeling (PLS-SEM, the predictive measurement model is prepared based on a guideline provided by (Hair et al., 2016), while the aim of this study is to develop a predictive model by focusing on highlighting the variance of the dependent variable when accessing the model.

\section{Descriptive Analysis}

The analysis is discussed to establish a summary of the received data. A number of respondents $(\mathrm{N})$, mean, standard deviation and a number of items, explain the relationship between blended learning and students' satisfaction. This section identifies the demographic profiles of the respondents who are currently studying at the AOU in KSA's branches. The questions that are provided to them are comprised of respondents' gender, age, college, level and corresponding branch.

\section{The Demographic Profiles of Respondents}

Table 1 illustrates the subject characteristics and background information, such as the gender, age, college, level, and branch that are collected from a sample of 221 undergraduate students in the university. Most 
of the students who participated in the questionnaire are female students, reaching $68.8 \%$ ( $\mathrm{N}=152$ female students), and male students reaching $31.2 \%$ ( $\mathrm{N}=69$ male students). The respondents who are involved in this study are within the age group of 20 years old or less of $18.1 \%(\mathrm{~N}=40), 21-30$ years old of $70.1 \%$ $(\mathrm{N}=155), 31-40$ years old of $8.6 \%(\mathrm{~N}=19)$ and more than 40 years old of $3.2 \%(\mathrm{~N}=7)$. In terms of their colleges, the faculty of computer studies possess the highest respondents reaching $45.2 \%(\mathrm{~N}=100)$, followed by the faculty of business studies reaching $41.6 \%(\mathrm{~N}=92)$, the faculty of language studies reaching $11.8 \%$ $(\mathrm{N}=26)$ and the lowest percentage from the faculty of education studies reaching $1.4 \%(\mathrm{~N}=3)$. As for the respondents' levels, the majority of them are within Level 3, which reaches 36.2\% ( $\mathrm{N}=80)$ and the lowest percentage belongs to the intensive English courses, reaching 3.2\% ( $\mathrm{N}=7)$. Most of the respondents are based in Dammam's branch reaching $44.8 \%(\mathrm{~N}=99)$.

Table 1. The demographic profile

\begin{tabular}{|c|c|c|c|}
\hline Demographic & & Frequency & Percent \% \\
\hline \multirow{2}{*}{ Gender } & Female & 152 & 68.8 \\
\hline & Male & 69 & 31.2 \\
\hline \multirow{4}{*}{ Age } & 20 years or less & 40 & 18.1 \\
\hline & $21-30$ years & 155 & 70.1 \\
\hline & $31-40$ years & 19 & 8.6 \\
\hline & More than 40 years & 7 & 3.2 \\
\hline \multirow{4}{*}{ College } & Faculty of Business Studies & 92 & 41.6 \\
\hline & Faculty of Computer Studies & 100 & 45.2 \\
\hline & Faculty of Education Studies & 3 & 1.4 \\
\hline & Faculty of Language Studies & 26 & 11.8 \\
\hline \multirow{5}{*}{ Level } & Expected to graduate & 71 & 32.1 \\
\hline & Intensive English Courses & 7 & 3.2 \\
\hline & Level 1 & 20 & 9.0 \\
\hline & Level 2 & 43 & 19.5 \\
\hline & Level3 & 80 & 36.2 \\
\hline \multirow{6}{*}{ Branch } & Ahsa & 5 & 2.3 \\
\hline & Dammam & 99 & 44.8 \\
\hline & Hail & 4 & 1.8 \\
\hline & Jeddah & 46 & 20.8 \\
\hline & Madinah & 8 & 3.6 \\
\hline & Riyadh & 59 & 26.7 \\
\hline
\end{tabular}

\section{Normality}

The normality test is a test that is used to measure the normal distribution of a dataset. The primary criterion of trials for assessing the normality is the Kolmogorov Smirnov and Shapiro-Wilk tests. With the large sample size ( $>40)$, the Kolmogorov-Smirnov test is used to evaluate the normality where the Shapiro-Wilk test is used for the sample size $(<40)$. While this presents the study sample size of $14(>40)$, the KolmogorovSmirnov test is used to determine the normality of data. To examine normalcy, a non-significant result ( $>$.05) indicates the normal distribution. In this regard, the parametric test is used for statistical analysis purposes. However, the significant values $(\mathrm{p}<.05)$ is still considered as a normal distribution where there is no high differences for the comparisons between the two mean values' differences (mean and $5 \%$ mean trimmed), and the value of the skewness and kurtosis is within the range \pm 1 . Table 2 indicates that the entire variables have no significant values $(p>0.05)$. Although the significance value of all variables is not normally distributed, the differences of the two mean values compared do not differ, and the amount of skewness and kurtosis are within the range \pm 1 . For the ELIB, the two mean values reach 2.620 and 2.5944 . 
For the MOD, the two mean values reach 2.760 and 2.74444, and for the INST, the two mean values reach 2.885 and 2.8688. As for the LMS, the two mean values reach 2.489 and 2.4356 . The two mean values for the FORM reach 2.773 and 2.7477, meanwhile, the two mean values reach 2.773 and 2.7471 for the F2F. Finally, the two mean values for the SS reach 2.752 and 2.7222 . The whole variables have the same number of skewness and kurtosis within the range \pm 1 . In conclusion, all data variables are considered as normally distributed based on the criterion of normality.

Table 2. The Performed normality tests of variables based on the Kolmogorov-Smirnov test.

\begin{tabular}{cccccccc}
\hline \multicolumn{7}{c}{ The Kolmogorov-Smirnov Test } \\
\hline ELIB & Statistic & df & Sig. & Mean & 5\% Trimmed mean & Skewness & Kurtosis \\
MOD & 0.106 & 221 & $0.000^{*}$ & 2.620 & 2.5944 & 0.164 & 0.326 \\
INST & 0.096 & 221 & $0.000^{*}$ & 2.760 & 2.7444 & 0.164 & 0.326 \\
LMS & 0.127 & 221 & $0.000^{*}$ & 2.885 & 2.8688 & 0.164 & 0.326 \\
SIS & 0.140 & 221 & $0.000^{*}$ & 2.489 & 2.4356 & 0.164 & 0.326 \\
FORM & 0.126 & 221 & $0.000^{*}$ & 2.686 & 2.6546 & 0.164 & 0.326 \\
F2F & 0.170 & 221 & $0.000^{*}$ & 2.773 & 2.7477 & 0.164 & 0.326 \\
SS & 0.180 & 221 & $0.000^{*}$ & 2.773 & 2.7471 & 0.164 & 0.326 \\
\hline
\end{tabular}

\section{The Comon Method Variance}

The common method variance is applied by using the SPSS where Table 3 demonstrates that the difference reaches $32 \%$, which can be seen that it could not affect the data. If the percentage exceeds $50 \%$, it could be biased in managing the involved data.

Table 3. The common method variance.

\begin{tabular}{ccccccc}
\hline \multirow{2}{*}{ Factor } & \multicolumn{3}{c}{ Initial Eigenvalues } & \multicolumn{3}{c}{ Extraction Sums of Squared Loadings } \\
\cline { 2 - 6 } & Total & \% of variance & Cumulative \% & Total & \% of variance & Cumulative \% \\
\cline { 2 - 6 } 1 & 5.588 & 69.853 & 69.853 & 5.248 & 31.946 & 31.946 \\
2 & .535 & 6.694 & 76.546 & & \\
3 & .507 & 6.341 & 82.887 & & \\
4 & .392 & 4.894 & 87.781 & & \\
5 & .378 & 4.720 & 92.501 & & \\
6 & .243 & 3.037 & 95.538 & & \\
7 & .182 & 2.275 & 97.812 & & \\
8 & .175 & 2.188 & 100.000 & & \\
\hline
\end{tabular}

\section{Assesment of the Measurement Model}

Following the reflective measurement model, the convergent validity and discriminant validity are analysed as highlighted in the following subsections.

\section{Convergent Validity}

The convergent validity refers to the degree for which it constructs indicators' converge or shares some specific variances (Ramayah et al/N/., 2018) The factors that determine the convergent validity are comprised of, as suggested by (Hair et al., 2017), the factor loading, Average Extracted Variance (AVE) and Composite Reliability (CR). Bagozzi \& Yi (1988)O declared that the number should be 0.5 or higher. Table 4 presents the indicator loadings, AVE and CR. No items are omitted here since all loadings exceed the 0.5 threshold 
(Hair et al., 2017). Moreover, the entire definitions are at or above the CR and AVE minimum cut-off threshold values, and restrict the CRs to be greater than 0.5 and all AVEs to be greater than 0.5 (Hair et al., 2017). It can be inferred from this that the constructs in the analysis meet the criteria of reliability and convergent validity.

Table 4. Convergent Validity.

\begin{tabular}{cccc}
\hline & Loadings & Composite Reliability & Average Variance Extracted (AVE) \\
\hline ELIB & 1.000 & 0.953 & 0.745 \\
F2F & 1.000 & 0.949 & 0.727 \\
FORM & 1.000 & 0.941 & 0.763 \\
INST & 1.000 & 0.944 & 0.706 \\
LMS & 1.000 & 0.956 & 0.757 \\
MOD & 1.000 & 0.923 & 0.632 \\
SIS & 1.000 & 0.944 & 0.708 \\
SS & 1.000 & 0.946 & 0.685 \\
\hline
\end{tabular}

\section{Discriminant Validity}

The discriminant validity is measured based on a study that is performed by Hair et al. (2017). It refers to the degree for which the items vary across different structures or steps. In Fornell \& Larcker (1981) research, a guideline claiming approach in which all measures should be highly charged on their own is proposed where the average difference that is shared between the construct should be higher than the difference shared between the constructs. The model fulfils the rule such that constructing the AVE square root is found higher than the items and the correlations with other constructs (see Table 5).

Table 5. Discriminant Validity.

\begin{tabular}{ccccccccc}
\hline & ELIB & F2F & FORM & INST & LMS & MOD & SIS & SS \\
\hline ELIB & $\mathbf{0 . 8 4 9}$ & & & & & & & \\
F2F & 0.633 & $\mathbf{0 . 8 5 3}$ & & & & & & \\
FORM & 0.559 & 0.684 & $\mathbf{0 . 8 8 6}$ & & & & & \\
INST & 0.580 & 0.612 & 0.596 & $\mathbf{0 . 8 7 1}$ & & & & \\
LMS & 0.625 & 0.669 & 0.534 & 0.595 & $\mathbf{0 . 8 7 0}$ & & & \\
MOD & 0.723 & 0.653 & 0.617 & 0.695 & 0.720 & $\mathbf{0 . 8 4 1}$ & & \\
SIS & 0.598 & 0.643 & 0.610 & 0.584 & 0.813 & 0.688 & $\mathbf{0 . 8 3 3}$ & \\
SS & 0.563 & 0.756 & 0.653 & 0.649 & 0.622 & 0.656 & 0.644 & $\mathbf{0 . 8 2 8}$ \\
\hline
\end{tabular}

\section{Assessment of the Structural Model (Inner Model)}

The structural model is examined after determining the suitability of the measurement model (Harun, et al., 2015) and after testing the hypothesis. The structural model indicates that there is a causal connection among the research model's latent constructs. The structural model is firstly evaluated by defining the model's predictive capacity, and secondly, possible correlations are tested among the latent constructs that are suggested in the research model (Hair et al., 2016). The discriminant validity of cross-loadings is highlighted in Table 6. The discriminant validity is further checked with the cross-loading criterion. Based on this criterion, the external loadings of an indicator pertaining to its associated constructs should be higher than the other remaining constructs in order to ensure that the latent variable can explain the variance of its own indicators more efficiently than the variance of the other variables (Hair et al., 2016). Consequently, the results depicted in Table 6 demonstrate that the discriminant validity is acceptable for the entire constructs. 
Table 6. The results of discriminant validity: cross-loadings.

\begin{tabular}{|c|c|c|c|c|c|c|c|c|}
\hline & ELIB & $\mathrm{F} 2 \mathrm{~F}$ & FORM & INST & LMS & MOD & SIS & SS \\
\hline ELIB1 & 0.859 & 0.581 & 0.492 & 0.529 & 0.604 & 0.675 & 0.498 & 0.501 \\
\hline ELIB2 & 0.874 & 0.535 & 0.477 & 0.445 & 0.548 & 0.592 & 0.481 & 0.446 \\
\hline ELIB3 & 0.868 & 0.498 & 0.515 & 0.462 & 0.520 & 0.643 & 0.523 & 0.460 \\
\hline ELIB4 & 0.848 & 0.539 & 0.433 & 0.457 & 0.531 & 0.571 & 0.550 & 0.495 \\
\hline ELIB5 & 0.793 & 0.528 & 0.455 & 0.562 & 0.442 & 0.583 & 0.478 & 0.479 \\
\hline F2F1 & 0.581 & 0.822 & 0.657 & 0.608 & 0.552 & 0.587 & 0.576 & 0.647 \\
\hline F2F2 & 0.526 & 0.892 & 0.630 & 0.563 & 0.560 & 0.553 & 0.536 & 0.660 \\
\hline F2F3 & 0.572 & 0.878 & 0.648 & 0.537 & 0.582 & 0.599 & 0.583 & 0.651 \\
\hline F2F4 & 0.544 & 0.867 & 0.521 & 0.489 & 0.568 & 0.612 & 0.514 & 0.632 \\
\hline F2F5 & 0.495 & 0.863 & 0.550 & 0.474 & 0.598 & 0.531 & 0.551 & 0.657 \\
\hline F2F6 & 0.518 & 0.846 & 0.565 & 0.499 & 0.559 & 0.515 & 0.531 & 0.672 \\
\hline F2F7 & 0.549 & 0.796 & 0.505 & 0.480 & 0.572 & 0.498 & 0.547 & 0.583 \\
\hline FORM1 & 0.451 & 0.597 & 0.924 & 0.506 & 0.420 & 0.532 & 0.549 & 0.611 \\
\hline FORM2 & 0.536 & 0.609 & 0.898 & 0.542 & 0.502 & 0.612 & 0.515 & 0.566 \\
\hline FORM3 & 0.510 & 0.586 & 0.879 & 0.595 & 0.460 & 0.533 & 0.555 & 0.604 \\
\hline FORM4 & 0.486 & 0.639 & 0.841 & 0.465 & 0.520 & 0.510 & 0.543 & 0.527 \\
\hline INST1 & 0.533 & 0.558 & 0.547 & 0.835 & 0.552 & 0.636 & 0.551 & 0.525 \\
\hline INST2 & 0.537 & 0.549 & 0.511 & 0.835 & 0.539 & 0.616 & 0.552 & 0.570 \\
\hline INST3 & 0.541 & 0.525 & 0.566 & 0.905 & 0.524 & 0.630 & 0.529 & 0.575 \\
\hline INST4 & 0.475 & 0.548 & 0.493 & 0.907 & 0.545 & 0.599 & 0.526 & 0.594 \\
\hline INST5 & 0.444 & 0.486 & 0.483 & 0.869 & 0.428 & 0.547 & 0.385 & 0.558 \\
\hline LMS1 & 0.533 & 0.547 & 0.436 & 0.568 & 0.844 & 0.634 & 0.709 & 0.533 \\
\hline LMS2 & 0.499 & 0.576 & 0.437 & 0.527 & 0.882 & 0.647 & 0.713 & 0.550 \\
\hline LMS3 & 0.583 & 0.632 & 0.550 & 0.545 & 0.896 & 0.682 & 0.709 & 0.616 \\
\hline LMS4 & 0.518 & 0.576 & 0.445 & 0.482 & 0.885 & 0.603 & 0.723 & 0.515 \\
\hline LMS5 & 0.527 & 0.568 & 0.447 & 0.476 & 0.905 & 0.607 & 0.715 & 0.508 \\
\hline LMS6 & 0.540 & 0.625 & 0.450 & 0.501 & 0.890 & 0.604 & 0.720 & 0.556 \\
\hline LMS7 & 0.602 & 0.536 & 0.476 & 0.517 & 0.782 & 0.600 & 0.662 & 0.494 \\
\hline MOD1 & 0.602 & 0.540 & 0.517 & 0.570 & 0.588 & 0.831 & 0.568 & 0.540 \\
\hline MOD2 & 0.622 & 0.560 & 0.567 & 0.588 & 0.642 & 0.890 & 0.569 & 0.575 \\
\hline MOD3 & 0.609 & 0.471 & 0.423 & 0.619 & 0.610 & 0.833 & 0.604 & 0.476 \\
\hline MOD4_ & 0.638 & 0.600 & 0.528 & 0.599 & 0.658 & 0.868 & 0.600 & 0.592 \\
\hline MOD5 & 0.567 & 0.557 & 0.540 & 0.548 & 0.525 & 0.775 & 0.552 & 0.557 \\
\hline SIS1 & 0.472 & 0.542 & 0.439 & 0.504 & 0.771 & 0.575 & 0.835 & 0.573 \\
\hline SIS2 & 0.505 & 0.544 & 0.470 & 0.497 & 0.789 & 0.605 & 0.884 & 0.559 \\
\hline SIS3 & 0.490 & 0.489 & 0.524 & 0.441 & 0.566 & 0.529 & 0.794 & 0.484 \\
\hline SIS4 & 0.460 & 0.525 & 0.490 & 0.482 & 0.650 & 0.592 & 0.845 & 0.497 \\
\hline SIS5 & 0.559 & 0.571 & 0.621 & 0.502 & 0.592 & 0.560 & 0.806 & 0.558 \\
\hline SS1 & 0.506 & 0.712 & 0.597 & 0.487 & 0.594 & 0.568 & 0.613 & 0.810 \\
\hline SS2 & 0.494 & 0.676 & 0.553 & 0.528 & 0.566 & 0.601 & 0.521 & 0.817 \\
\hline SS3 & 0.465 & 0.620 & 0.543 & 0.669 & 0.458 & 0.523 & 0.462 & 0.848 \\
\hline SS4 & 0.477 & 0.541 & 0.468 & 0.445 & 0.470 & 0.538 & 0.578 & 0.803 \\
\hline SS5 & 0.449 & 0.616 & 0.626 & 0.592 & 0.491 & 0.524 & 0.553 & 0.871 \\
\hline SS6 & 0.394 & 0.565 & 0.431 & 0.491 & 0.501 & 0.495 & 0.464 & 0.819 \\
\hline
\end{tabular}




\section{Significant Value between Blended Learning and Students' Satisfaction}

In Table 7, the SMART-PLS tool is used to show as to whether or not there are any significant relationship between the blended learning factors/variables that achieve students' satisfaction. It is found to be proven from the obtained results that there is a significant relationship between students' satisfaction and INST and F2F where the p-value reaches 0.000 and FORM with a p-value that equals to 0.024 (a threshold of P value $<0.05)$. Similarly, the MOD demonstrates a significant relationship with students' satisfaction for a p-value of 0.042 and SIS reflects similar significance with a p-value of 0.020 . However, the ELIB shows no significant relationship with students' satisfaction since the p-value reaches $0.230(>0.05)$. Moreover, the LMS shows no significant relationship with students' satisfaction as its p-value reaches $0.470(>0.05)$.

Table 7. The relationship between blended learning and students' satisfaction.

\begin{tabular}{ccccccc}
\hline Hypotheses & Path Coefficient & Sample Mean (M) & STDEV & T Statistics & P Values & Decision \\
\hline ELIB $>$ SS & -0.046 & -0.048 & 0.062 & 0.740 & 0.230 & Not Supported \\
F2F $>$ SS & 0.427 & 0.425 & 0.073 & 5.858 & $\mathbf{0 . 0 0 0}$ & Supported \\
FORM $>$ SS & 0.125 & 0.123 & 0.063 & 1.990 & $\mathbf{0 . 0 2 4}$ & Supported \\
INST $>$ SS & 0.182 & 0.182 & 0.051 & 3.546 & $\mathbf{0 . 0 0 0}$ & Supported \\
LMS $>$ SS & -0.006 & -0.003 & 0.080 & 0.075 & 0.470 & Not Supported \\
MOD $>$ SS & 0.115 & 0.116 & 0.066 & 1.730 & $\mathbf{0 . 0 4 2}$ & Supported \\
SIS $>$ SS & 0.140 & 0.144 & 0.068 & 2.053 & $\mathbf{0 . 0 2 0}$ & Supported \\
\hline
\end{tabular}

Additionally, Table 7 and Figure 3 illustrate the result of the Bootstrapping that is carried out to determine the significance of the relationships between blended learning and its sub-constructs on the endogenous variable for students' satisfaction. The assessment is based on the research hypothesis mentioned earlier in this paper. Accordingly, it is shown that all research hypotheses are supported except for Hypothesis $\mathrm{H} 1-\mathrm{a}$ and $\mathrm{H} 1-\mathrm{e}$. In fact, this leads to the conclusion that E-library and LMS do not possess a significant relationship with students' satisfaction.

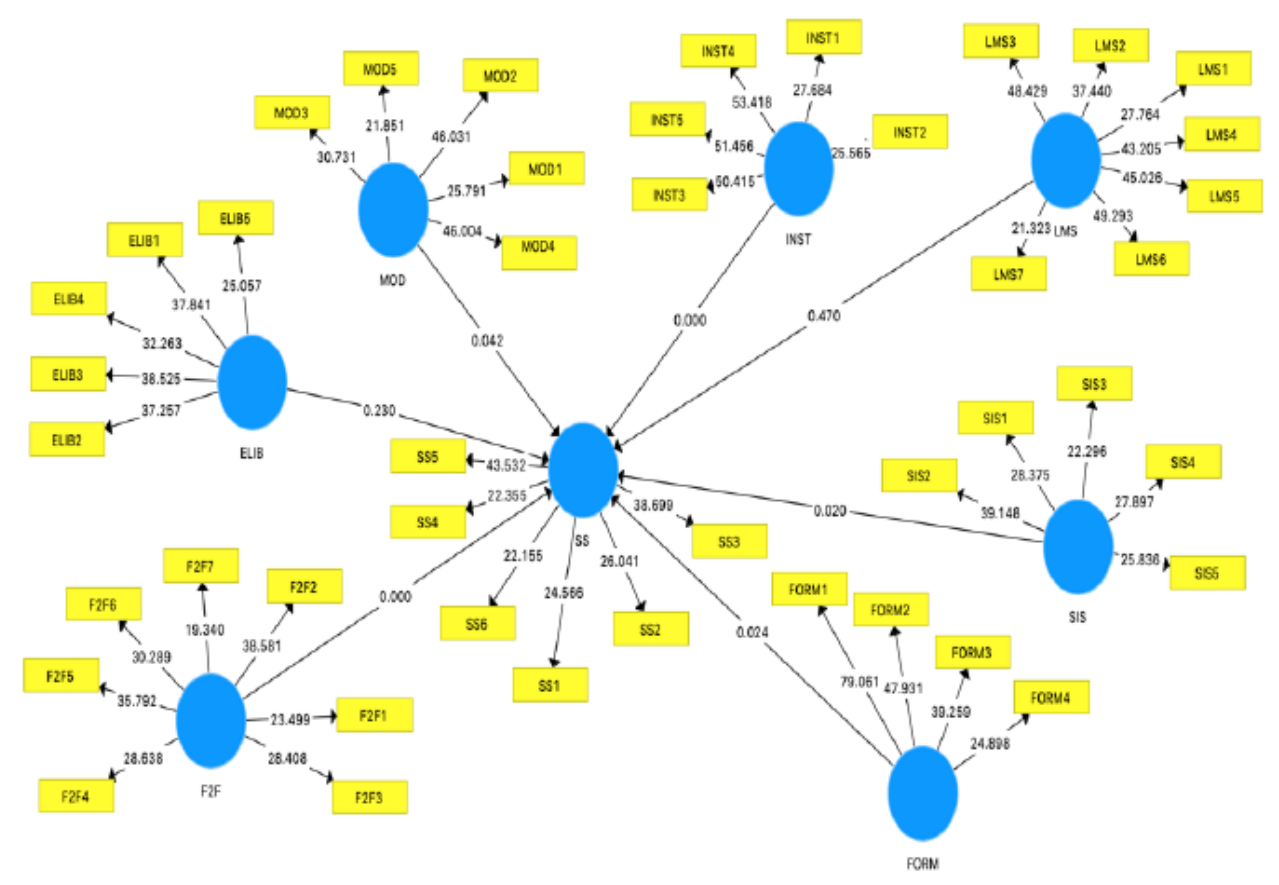

Figure 3. The relationship between blended learning and students' satisfaction. 


\section{NARRATIVE ANALYSIS AND DISCUSSION}

The current study is conducted in order to obtain an overall perspective on the relationship between blended learning and students' satisfaction. In this context, researchers have considered all sub-variables, including the instructor, modules, E-library, Learning Management System (LMS), Student Information System (SIS), online discussion forum and face-to-face classes that represent the blended learning variables for investigating the relationship between blended learning and students' satisfaction. In the previous section, the researchers have conducted the data analysis by identifying the descriptive analysis in terms of the demographic profile. It is found to be proven from the obtained results that the female respondents represents the majority of respondents who participated in this study compared to the male respondents (Kane \& Macaulay, 1993). Kane \& Macaulay (1993) stated that female respondents tend to answer in a positive manner in most of the questions compared to male respondents. Additionally, it can be inferred that male respondents have a tendency to not answer the questionnaire in a serious manner. Moore et al. (2002) indicated that female respondents are more likely to participate than male respondents are. Meanwhile, the respondents who are aged between 21 to 30 years old represent the majority of this study, and are aligned with some other researchers who mention that younger people are likely to voluntarily participate in a given research compared to older people (Goyder, 1986; Moore et al., 2002).

The data analysis reveals that students from the AOU provide positive responses toward the Face-to-Face (F2F) and Videoconferencing Classes that form an indicator to their satisfaction. The outcome demonstrates a rigid and moderate relationship to students' satisfaction. The F2F classes possesses rigid and positive associations to students' satisfaction based on a research performed by Tratnik et al. (2019). Moreover, the outcome demonstrates that the integrated learning of F2F provides further effective means of communicating students' information through different forms of pedagogies that can inspire them to pursue their studies more attentively and creatively (Roach \& Lemasters, 2006). This study is similar to the previous research carried out by Kintu et al. (2017), which stated that there is a significant relationship between the F2F and students' satisfaction. This can also be supported by the previous study, which recorded the average mean score of the F2F towards students' satisfaction. The results show that the respondents are satisfied with the F2F classes. This indicates that students possess a moderate level of satisfaction when applying the blended learning approach as a teaching process. Further efforts are required to make students satisfied with what they gain in their face-to-face classes or online classes and enhance their attendance's rate. The Face-to-Face and Videoconference Classes (F2F) represent the most effective way for AOU's students, as the F2F classes possess a reliable and stable connection with students' satisfaction in comparison with others. Since the results from respondents indicate to a 'neutral' form, the AOU must find the most effective method for transferring from average to rigid relationships. This is, in fact, important as the university can gain a better reputation by improving its blended learning and achieving students' satisfaction in the blended learning approach.

Moreover, it is shown from the data analysis that positive students' responses are achieved toward the instructor factor, which form an indicator to their satisfaction. The outcome demonstrates positive relationship between the instructor and students' satisfaction. These results are confirmed by an earlier research conducted by Joel \& Christina (2018), which conclud that the quality of the blended learning system and instructors possess a significant positive effect on learners' satisfactions. According to a study performed by Eastman et al. (2017), it can be inferred that the perceived learning approach is positively related to the instructor-to-student interaction. The Instructor is a major factor, which affects the students' satisfaction based on several blended learning approaches. Additionally, this study is similar to a previous research conducted in (Ismail, 2018), which states that the module instructor affects and increases students' satisfaction with the blended learning approach that has a significant relationship with the students. The results of the current study can also be supported by a previous study, which reveals that the instructor is an important factor that directly affects students' satisfaction on this approach (Naaj, Nachouki, \& Ankit, 2012). The results demonstrate that students are satisfied with the instructor. This can lead to conclude that instructors are motivators, available for consultations, their response times are adequate, and adequate feedbacks can be provided to their students. Consequently, the module instructors have a significant relationship with students' satisfaction.

According to the results of the investigated data analysis, students are satisfied with the modules and materials they receive for studying their courses within the blended learning approach. In fact, this approach 
provides the suitable environment, which aims at delivering the modules' continents to students. Based on the studies carried out by Hadullo, Omwenga, \& Oboko (2017), an efficient and adequate quality should be obtained for the resources and materials pertaining to the involved modules. Similarly, Rockinson-Szapkiw et al. (2016) indicate that a valuable connection is performed with the contents of students courses based on the perceived learning approach. This action ensures that modules should be rich and accessed anytime and anywhere, and should be frequently improved (Khan et al., 2012; Shivam \& Singh, 2015). In the same context, it is suggested by Rovai \& Baker (2005) that students' perspectives can be realised based on their self-reported perceived learning by improving their performances on many different educational modules. Further, a research study conducted by (Kavitha \& Jaisingh (2019) indicates that the success of blended learning can be directly affected by the quality of the provided material of the modules. Moreover, a research study produced by Afacan (2018) investigates the direct and indirect effects of blended learning on students' satisfaction and performances of the entire modules. These modules improve students' satisfaction where their designs can directly put an impact on students' performances, which improve students' satisfaction with blended learning. Similar research is investigated by Giannousi et al. (2009) for exploring students' satisfaction with different blended learning modules. The results show that students' satisfaction is higher than average. The results demonstrate that students are satisfied with these modules where this indicates that modules are made available, accessible anytime and anywhere. Hence, the assessments of the modules cover the entire learning outcomes, which are related to these modules.

Alzahrani (2017) pointed out that the students of four leading universities in the KSA are satisfied with applying online forums through their education. In this study, it is also shown that the students are satisfied with using them through their learning. Similar research conducted by Fu et al. (2017) shows that online discussion forums can have a significant impact on blended learning environment, and can contribute to improve students' learning outcomes and progress bsed on involving an important rule as a communication link between students and tutors. Online forums represent the fundamental factors that contribute in practicing blended learning for which tutors can post different topics related to the modules they are delivering. These can enable the students to interact with their assigned tutors and other students in an easy and efficient manner.

The Student Information System (SIS) is an important system that contributes in evolving and administrating many different institutions of the higher education (Gurkut \& Nat, 2017). This system shows that the satisfaction has influenced directly on students' satisfaction based on the provided information quality and indirectly by information quality and system quality when a decision making is used as a mediator (Gurkut \& Nat, 2017). The study demonstrates that the students are satisfied with the SIS as it possess several functions that can assist them in performing their tasks, such as registering modules, accessing the study plan, and etc. In the context of the research, the SIS provides easy user-friendly interfaces where this efficient advantage can provide the ability for students to easily make use of the SIS when required and valuable services can be accordingly achieved and supported to them in efficient and desirable manners.

Based on the obtained results, it is found to be proven that the variables, namely, LMS and E-library, produce $P$ values of 0.454 and 0.239 , respectively. This reveals that the two obtained values are greater than the $\mathrm{P}$ value threshold, which is 0.05 , where the two values imply that negative responses emerge for the two values. In fact, the reason behind this is that most students find that the LMS and E-library factors are adversely affecting their tasks as the two systems remain frequently stuck due to a number of technical issues.

Furthermore, Holley \& Powell (2004) state that $53.8 \%$ of respondents are unable to comprehend the 'grasp' of answering different questions when using their E-library system. In the context of this paper, AOU's students are also unaware of understanding different questions that are incurred in such a system. The results of the current study are confirmed by the results of Aljaraideh and Rabee (2018) who conclude that students are moderately satisfied by the Elibrary resources.

However, Najmi et al. (2016) indicate that respondents are more satisfied with their electronic resources, unlike the results of the current study, which reveal that they are unsatisfied with the LMS since these systems remain frequently unmanageable in an effective manner. On the contrast, Ohliati \& Abbas (2019) conclude that the dominant factor, which impacts students' satisfactions with LMS represents the service quality. On the other hand, it is argued by Islam (2014) that their involved respondents are dissatisfied with the 
LMS factor, and hence, further trainings must render them to enhance their perceptions in being satisfied with this factor. Similar to Alzahrani (2017) declares that students are dissatisfied with the LMS for some grounds, such as different continuous system failures and the lack of acquiring an appropriated training experience. Additionally, it can be inferred from the study that is produced by Alzahrani (2017) that the system failure is not a reason to be taken into account. Nonetheless, this reason is significant in the current study since many students enrolled in a university are persistently complaining about their dissatisfaction with the system failure alongside their lack of being trained in managing the LMS and E-library systems.

To sum up, it could be concluded that these results are important to be studied and adopted by the university. This is because a more effective reputation is gained for the university by improving its blended learning approach and making its students satisfied with the blended learning process.

\section{LIMITATIONS AND FUTURE RESEARCH}

This research has provided an invaluable amount of information in order to explain the way the blended learning approach enhances students' satisfactions by proposing seven blended learning factors, which are assessed in terms of their impact on respondents' satisfactions. Although this study has indeed provided an insightful information, there are some encountered limitations that should be addressed for future studies in order to ensure that more insights can possibly highlight the investigated phenomenon.

Intially, as the data analysis demonstrates that the majority of the respondents' are female students with the age of 20-30 years old, the moderating effects of the respondents' demographic characteristics such as gender, age and technical skills level are not included in the research framework. The inclusion of these variables in for the future studies could enrich the research findings even further.

Additonally, although the questionnaires of the study are effectively designed and reviewed, and are validated through a pilot study that is approved by university educationalists, it is a new questionnaire that is not validated in other environments and countries. Thus, the replications of the current study when using the same questionnaire is recommended to validate its usability for assessing students' satisfaction via the blended learning approach.

Furthermore, this study has been undertaken among the six Saudi branches of the AOU. Thus, the replication of the research in other regional branches (i.e. Kuwait, Bahrain, Lebanon, Egypt, and so on) can provide a more effective insight into students' satisfactions with based on using the blended learning approach throughout the entire AOU's branches.

Moreover, the results of this research reveal that students' dissatisfactions with the LMS and E-library resources are provided by the university, and their technical skills are considered as a control variable within the proposed framework. Nonethtless, students with higher technical skills can use these resources more easily in comparison with those possessing lower technical skills. Hence, the inclusion of students' technical skills as a control variable can reveal more effective insights into students' satisfaction as confirmed by earlier studies (Mihanovic, Batinic \& Pavicic, 2016), particularly, for those factors in which students are found to be dissatisfied with the LMS and E-Library resources.

To conclude, future studies should measure how the blended learning approach assists students in improving their skills and performances within this approach. Additionally, such studies could also include significant comparisons among their plans for using the LMS between the first and final-year students on a regular basis. In fact, this approach could enable future researchers to understand the components related to students' satisfactions and encourage effective improvements in the quality of any offered mixed learning courses. Consequently, further researches should be taken into account to find the reasons behind different levels of satisfaction within these areas. Finally, it is deduced that being able to understand students' demands when students are supported by mixed learning courses where fostering a positive learning experience can be crucial to the overall success of the mixed learning within the university. 


\section{CONCLUSION}

The blended learning approach has currently become an essential norm, and the conventional method of teaching is still applied by providing several flexibilities for students when proceeding further along with their studies. Moreover, students' satisfactions with the blended learning approach is essential since it can put an impact on their motivation, and thus, their progress and completion rates are improved.

Assessing students' satisfactions is also essential for universities and educational institutions as they can be used to assess programs and courses, and to forecast different attrition rates for students to some extent. This paper is performed to assess students' satisfactions with the blended learning approach they receive within a private university in Saudi Arabia. It is found to be proven from the obtained results that students are mostly satisfied with face-to-face and video conference classes, instructors, modules, student information system and online discussion forums. Nevertheless, students are unsatisfied with their university's learning management system nor their university's e-library system. Furthermore, the results demonstrate that students perceive face-to-face and video conferencing classes more practically in the AOU. The reason behind this is that the face-to-face method enables to spark their motivations directly toward encouraging them in proceeding efficiently along with their studies.

Apart from that, this method provides a significant value to the university when evaluating their current practices in integrating technology and digital platform for enhancing the capabilities toward teaching and learning, particularly, after the current COVID19 pandemic. Not only does the diversified technique assist students in being more attentive and satisfied with it, but can also generate various creative and innovative ideas from instructors through their teaching styles.

Acknowledgements: The authors of this manuscript would like to express their appreciations and gratitude to the Arab Open University in Saudi Arabia for supporting this research.

\section{BIODATA and CONTACT ADDRESSES of AUTHORS}

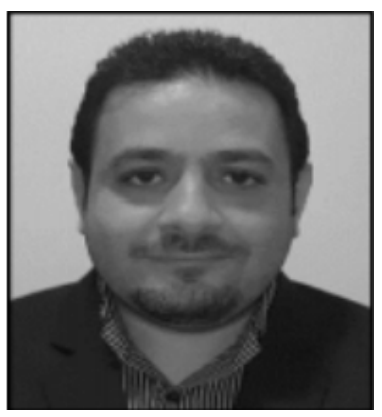

Hussein AL-BAZAR received his PhD Degree in computer networks especially in network security and monitoring from Universiti Sains Malaysia (USM) in 2010. He has published many research papers in International Journals and Conferences with high reputation. His research interests lie in advanced Internet security, and information security, E-learning, and blended learning. Currently, Dr. Al-Bazar is an Assistant Professor at Faculty of Computer Studies, Arab Open University, Dammam, Saudi Arabia.

Hussein AL-BAZAR

Faculty of Computer Studies

Address: Arab Open University, 32211, Dammam, Saudi Arabia

Phone: ++966 138315415, Ext.:242

E-mail: halbazar@arabou.edu.sa 


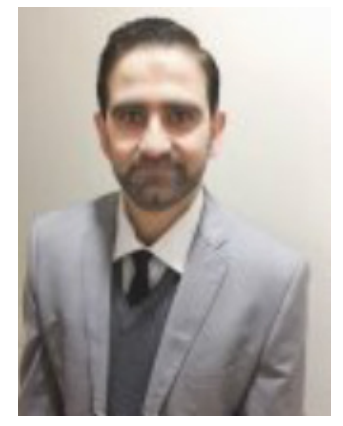

Hussein ABDEL-JABER received his MSc in Mobile Computing from University of Bradford, U.K. in 2004 and from the same university he received his $\mathrm{PhD}$ in Computing. His research interests are in congestion control of networks (i.e. internet), queueing networks analysis using discrete-time queues or continuous-time queues, fuzzy logic control, machine learning, security and e-learning. He has several published research papers in the previous research interests.

Hussein ABDEL-JABER

Faculty of Computer Studies

Address: Arab Open University, 32211, Dammam, Saudi Arabia

Phone: ++966 138315415, Ext.:289

E-mail: habdeljaber@arabou.edu.sa

Ebtisam LABIB is an assistant Professor of Marketing and Consumer Behavior at Faculty of Business Studies, Arab Open University. Dr. Ebtisam gained her Ph.D. in Marketing in September, 2019. Her academic interest areas are Digital Marketing, consumer behavior, block chains, social media marketing, blended learning, open and distance learning.

\section{Ebtisam LABIB}

Faculty of Business Studies

Address: Arab Open University, 32211, Dammam, Saudi Arabia

Phone: ++966138315415, Ext.:281

E-mail: e.labib@arabou.edu.sa

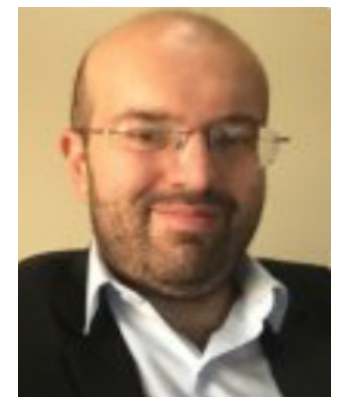

Mohammad AL-MADI has been awarded his $\mathrm{PhD}$ degree in computer sciences from Staffordshire University, UK in 2017. He is currently assigned as an assistant professor at the faculty of computer studies, Arab Open University, Jeddah's branch, Saudi Arabia. He has published a number of research articles in different refereed international journals. His research interests comprise, but are not limited to, data science, databases, data mining, cloud copmputing, internet of things, knowledge management, information overload, healthcare informatics, and many more.

\section{Mohammad AL-MADI}

Faculty of Computer Studies

Address: Arab Open University, Postal Code, Jeddah, Saudi Arabia

Phone: +966126823641 Ext.: 6097

E-mail:m.almadi@arabou.edu.sa 


\section{REFERENCES}

Afacan, Y. (2018). STUDENT EXPERIENCES OF BLENDED LEARNING IN INTERIOR ARCHITECTURE. Journal of Information Technology Education: Research, 17, 399-422.

ALJARAIDEH, Y., \& RABEE, A. (2018) STUDENTS'SATISFACTION WITH E-SERVICES AT JERASH UNIVERSITY. WEI International Academic Conference, 178-191.

Akyol, Z., \& Garrison, D. R. (2011). Understanding cognitive presence in an online and blended community of inquiry: Assessing outcomes and processes for deep approaches to learning. British Journal of Educational Technology, 42(2), 233-250.

Almarashdeh, I., Alsmadi, M., Jaradat, G., Thunibat, A., Albahussain, S., Qawqzeh, Y., . . . Eldaw, k. e. (2018). Looking Inside and Outside the System: Examining the Factors Influencing Distance Learners Satisfaction in Learning Management System. Journal of Computer Science, 14, 453-465. doi: $10.3844 /$ jcssp.2018.453.465

Alzahrani, M. (2017). Student satisfaction with using online discussion forums at Saudi universities. World Journal of Education, 7, 1-10. doi:10.5430/wje.v7n2p1

Anaraki, F. (2018). The Effectiveness Of Blended Learning: A Case Study. ABAC Journal, 38(2), 82-93.

Askar, P., Altun, A., \& Ilgaz, H. (2008). Learner satisfaction on blended learning. E-leader Krakow.

Bagozzi, R. P., \& Yi, Y. (1988). On the evaluation of structural equation models. Journal of the academy of marketing science, 16(1), 74-94.

Bahati, B., Fors, U., Hansen, P., Nouri, J., \& Mukama, E. (2019). Measuring Learner Satisfaction with Formative e-Assessment Strategies. International Journal of Emerging Technologies in Learning (iJET), 14(07), 61-79.

Bi, X., \& Shi, X. (2019). On the Effects of Computer-Assisted Teaching on Learning Results Based on Blended Learning Method. International Journal of Emerging Technologies in Learning (iJET), 14(01), 58-70.

Botha, J. (2018). Student satisfaction with a blended learning approach: implementation evaluation of three Honours programmes in Education. Stellenbosch: Stellenbosch University,

Bouilheres, F., McDonald, S., Nkhoma, C., \& Jandug-Montera, L. (2020). Defining student learning experience through blended learning. Education and Information Technologies, 1-21.

Collaco, C. M. (2017). Increasing student engagement in higher education. Journal of Higher Education Theory and Practice, 17(4).

Commissiong, M. A. (2020). Student Engagement, Self-Regulation, Satisfaction, and Success in Online Learning Environments. Retrieved from https://scholarworks.waldenu.edu/dissertations/8522

Eastman, J. K., Aviles, M., \& Hanna, M. D. (2017). Determinants of perceived learning and satisfaction in online business courses: An extension to evaluate differences between qualitative and quantitative courses. Marketing Education Review, 27(1), 51-62.

Eryilmaz, M. (2015). The Effectiveness Of Blended Learning Environments (Vol. 8).

Fornell, C., \& Larcker, D. F. (1981). Evaluating Structural Equation Models with Unobservable Variables and Measurement Error. Journal of Marketing Research, 18(1), 39-50. doi:10.2307/3151312

Friesen, N. (2012). Report: Defining Blended Learning. Retrieved from https://www.normfriesen.info/ papers/Defining_Blended_Learning_NF.pdf

Fu C, Qian D, Liu Q, Gao X (2017). Effect of online discussion forum in blended learning mode. Acad. J. Educ. Res. 5(10): 377-383

Ghaderizefreh, S., \& Hoover, M. L. (2018). Student Satisfaction with Online Learning in a Blended Course International Journal of Digital Society (IJDS), 9(3), 1393-1398. 
Giannousi, M., Vernadakis, N., Derri, V., Michalopoulou, M., \& Kioumourtzoglou, E. (2009). Students' satisfaction from blended learning instruction.

Goyder, J. (1986). Surveys on Surveys: Limitations and Potentialities. The Public Opinion Quarterly, 50(1), 27-41. Retrieved from www.jstor.org/stable/2748968

Gurkut, C., \& Nat, M. (2017). Important factors affecting student information system quality and satisfaction. EURASIA Journal of Mathematics, Science and Technology Education, 14(3), 923-932.

Hadullo, K., Omwenga, E., \& Oboko, R. (2017). A Model for Evaluating E-Learning Systems Quality in Higher Education in Developing Countries. International journal of education and development using information and communication technology, 13, 185.

Hair, J., Ringle, C., \& Sarstedt, M. (2012). Partial Least Squares: The Better Approach to Structural Equation Modeling? Long Range Planning, 45, 312-319. doi:10.1016/j.lrp.2012.09.011

Hair, J. F., Hult, G. T. M., Ringle, C., \& Sarstedt, M. (2016). A primer on partial least squares structural equation modeling (PLS-SEM): Sage publications.

Hair, J. F., Hult, G. T. M., Ringle, C., \& Sarstedt, M. (2017). A Primer on Partial Least Squares Structural Equation Modeling (PLS-SEM). Thousand Oaks: Sage. .

Harrell, K. B., \& Wendt, J. L. (2019). The Impact of Blended Learning on Community of Inquiry and Perceived Learning among High School Learners Enrolled in a Public Charter School. Journal of Research on Technology in Education, 51(3), 259-272. doi:10.1080/15391523.2019.1590167

Harun, A., Liew, T. S., Mohd Kassim, A. W., \& Sulong, R. S. (2015). Smartphone dependency and its impact on purchase behavior. Asian Social Science Journal, 11(26), 196-211.

Holley, R. P., \& Powell, R. R. (2004). Student satisfaction with electronic library resources at Wayne State University. Journal of Access Services, 2(1), 41-62.

Hutabarat, F., Hutabarat, R., \& Hutabarat, F. M. (2020). Factor Analysis of Students' Satisfaction with Academic Courses. HUMAN BEHAVIOR, DEVELOPMENT and SOCIETY, 21(1), 78-84.

Islam, A. (2014). Sources of satisfaction and dissatisfaction with a learning management system in postadoption stage: A critical incident technique approach. Computers in Human Behavior, 30. doi:10.1016/j.chb.2013.09.010

Ismail, A. M. A. (2018). Empowering Your Students Satisfaction with Blended Learning: A Lesson from the Arabian Gulf University Distance Teaching and Training Program. International Journal of Information and Education Technology, 8(2), 108-120.

Joel, S. M., \& Christina, R. (2018). Key factors in learners' satisfaction with the e-learning system at the University of Dar es Salaam, Tanzania. Australasian Journal of Educational Technology, 34(4). doi:10.14742/ajet.2993

Kane, E. W., \& Macaulay, L. J. (1993). Interviewer gender and gender attitudes. Public opinion quarterly, $57(1), 1-28$.

Kang, J., \& Seomun, G. (2018). Evaluating web-based nursing education's effects: A systematic review and meta-analysis. Western Journal of Nursing Research, 40(11), 1677-1697.

Kasim, N. N. M., \& Khalid, F. (2016). Choosing the Right Learning Management System (LMS) for the Higher Education Institution Context: A Systematic Review. International Journal of Emerging Technologies in Learning, 11(6).

Kara, A., Tanui, E., \& Kalai, J. (2016). Quality of academic resources and students' satisfaction in public universities in Kenya. Teaching and Educational Research, 15(10), 130-146.

Kaveevivitchai, C., Chuengkriankrai, B., Luecha, Y., Thanooruk, R., Panijpan, B., \& Ruenwongsa, P. (2009). Enhancing nursing students' skills in vital signs assessment by using multimedia computer-assisted learning with integrated content of anatomy and physiology. Nurse Education Today, 29(1), 65-72. 
Kavitha, R., \& Jaisingh, W. (2019). A study on the student experiences in blended learning environments. International Journal of Recent Technology and Engineering, 7, 183-186.

Kavitha, R. K., Jayalakshmi, V. J., \& Rassika, R. (2018). Collaborative learning in Computer Programming Courses using E-Learning Environments. International Journal of Pure and Applied Mathematics, 118(8), 183-189.

Keramidas, C. G. (2012). Are undergraduate students ready for online learning? A comparison of online and face-to-face sections of a course. Rural Special Education Quarterly, 31(4), 25-32.

Keskin, S., \& Yurdugul, H. (2019). Factors Affecting Students' Preferences for Online and Blended Learning: Motivational Vs. Cognitive. European Journal of Open, Distance and E-Learning, 22, 71-85. doi:10.2478/eurodl-2019-0011

Khan, A., Qayyum, N.-u., Shaik, M. S., Ali, A., \& Bebi, C. V. (2012). Study of Blended Learning Process in Education Context. I.J.Modern Education and Computer Science, 9, 23-29. doi:10.5815/ ijmecs.2012.09.03

Kintu, M. J., Zhu, C., \& Kagambe, E. (2017). Blended learning effectiveness: the relationship between student characteristics, design features and outcomes. International Journal of Educational Technology in Higher Education, 14(1), 7. doi:10.1186/s41239-017-0043-4

Lalima, \& Dangwal., K. L. (2017). Blended Learning: An Innovative Approach. Universal Journal of Educational Research 5(1), 129-136.

Larson, D. K., \& Sung, C.-H. (2009). Comparing student performance: Online versus blended versus faceto-face. Journal of Asynchronous Learning Networks, 13(1), 31-42.

Li, C., He, J., Yuan, C., Chen, B., \& Sun, Z. (2019). The effects of blended learning on knowledge, skills, and satisfaction in nursing students: A meta-analysis. Nurse Education Today, 82. doi:10.1016/j. nedt.2019.08.004

Lim, D. H., Morris, M. L., \& Kupritz, V. W. (2007). Online vs. blended learning: Differences in instructional outcomes and learner satisfaction. Journal of Asynchronous Learning Networks, 11(2), $27-42$.

Masrom, U. K., Alwi, N. A. N. M., \& Asshidin, N. H. N. (2019). Understanding Learners' Satisfaction in Blended Learning among Undergraduate Students in Malaysia. Universal Journal of Educational Research, 7(10), 2233-2238.

Mihanovic, Z., Batinic, A. B., \& Pavicic, J. (2016). THE LINK BETWEEN STUDENTS'SATISFACTION WITH FACULTY, OVERALL STUDENTS'SATISFACTION WITH STUDENT LIFE AND STUDENT PERFORMANCES. Review of Innovation and Competitiveness: A Journal of Economic and Social Research, 2(1), 37-60.

Moore, D. L., Tarnai, J., Groves, R. M., Dillman, D. A., Eltinge, J. L., \& Little, R. J. (2002). Survey nonresponse. In (pp. 197-211): John Wiley \& Sons, Ltd New York.

Naaj, M. A., Nachouki, M., \& Ankit, A. (2012). Evaluating Student Satisfaction with Blended Learning in a Gender-Segregated Environment. Journal of Information Technology Education: Research, 11, $185-200$.

Najmi, S., Jaafar, N., \& Paiz, R. (2016). STUDENTS' PREFERENCE FOR TOOLS ON LEARNING MANAGEMENT SYSTEM. International Young Scholars Journal of Language (IYSJL), 1, 10-20.

Ohliati, J., \& Abbas, B. S. (2019). Measuring students satisfaction in using learning management system. International Journal of Emerging Technologies in Learning (iJET), 14(04), 180-189.

Ramayah, T., Cheah, J., Chuah, F., Ting, H., \& Memon, M. (2018). Partial least squares structural equation modeling (PLS-SEM) using smartPLS 3.0. In An Updated Guide and Practical Guide to Statistical Analysis: Pearson.

Roach, V., \& Lemasters, L. (2006). Satisfaction with online learning: A comparative descriptive study. Journal of Interactive Online Learning, 5(3), 317-332. 
Rockinson-Szapkiw, A. J., Wendt, J., Whighting, M., \& Nisbet, D. (2016). The predictive relationship among the community of inquiry framework, perceived learning and online, and graduate students' course grades in online synchronous and asynchronous courses. International Review of Research in Open and Distributed Learning, 17(3), 18-35.

Roff, K. (2018). Student Satisfaction and/or Dissatisfaction in Blended Learning Environments. Frontiers in Education Technology, 1, 149. doi:10.22158/fet.v1n2p149

Roslina, A. T., Nur Shaminah, M. K., \& Sian-Hoon, T. (2013). Students' Satisfaction on Blended Learning: A Preliminary Study. Pertanika Journal of Social Science and Humanities, 21(3), 1119-1131.

Rovai, A. P., \& Baker, J. D. (2005). Gender differences in online learning: Sense of community, perceived learning, and interpersonal interactions. Quarterly Review of Distance Education, 6(1), 31.

Rovai, A. P., Wighting, M. J., Baker, J. D., \& Grooms, L. D. (2009). Development of an instrument to measure perceived cognitive, affective, and psychomotor learning in traditional and virtual classroom higher education settings. The Internet and Higher Education, 12(1), 7-13.

Sekaran, U., \& Bougie, R. (2016). Research methods for business: A skill building approach: John Wiley \& Sons.

Sherifi, I. (2015). IMPACT OF INFORMATION SYSTEMS IN SATISFYING STUDENTS OF THE UNIVERSITY: CASE STUDY FROM EPOKA UNIVERSITY. European Journal of Business and Social Science, 4, 167-175.

Sherman, H., Comer, L., Putnam, L., \& Freeman, H. (2012). Blended versus lecture learning: outcomes for staff development. Journal for Nurses in Professional Development, 28(4), 186-190.

Shivam, R., \& Singh, S. (2015). Implementation of Blended Learning in Classroom: A review paper. International Journal of Scientific and Research Publications, 5(11), 369-372.

Stefanic, I., Campbell, R. K., Russ, J. S., \& Stefanic, E. (2020). Evaluation of a blended learning approach for cross-cultural entrepreneurial education. Innovations in Education and Teaching International, 57(2), 242-254. doi:10.1080/14703297.2019.1568901

Tratnik, A., Urh, M., \& Jereb, E. (2019). Student satisfaction with an online and a face-to-face Business English course in a higher education context. Innovations in Education and Teaching International, 56(1), 36-45.

Umek, L., Keržic, D., Aristovnik, A., \& Tomaževic, N. (2015). Analysis of Selected Aspects of Students' Performance and Satisfaction in a Moodle-Based E-Learning System Environment. urasia Journal of Mathematics, Science and Technology Education, 11(6), 1459-1505. doi:https://doi.org/10.12973/ eurasia.2015.1408a

Wu, J.-H., Tennyson, R. D., \& Hsia, T.-L. (2010). A study of student satisfaction in a blended e-learning system environment. Computers \& Education, 55(1), 155-164. doi:https://doi.org/10.1016/j. compedu.2009.12.012

Zhai, X., Gu, J., Liu, H., Liang, J.-C., \& Tsai, C.-C. (2017). An experiential learning perspective on students' satisfaction model in a flipped classroom context. Journal of Educational Technology \& Society, 20(1), 198-210. 